\title{
Coordinated Outreach: A Model of STEAM Outreach Efforts
}

\section{Wendy Roldan, University of Washington, Human Centered Design \& Engineering}

Wendy Roldan is a PhD candidate in Human Centered Design and Engineering at the University of Washington studying equity in engineering education. Her work draws from the fields of engineering education, design, and learning sciences.

Ms. Taryn Shalini Bipat, University of Washington, Human Centered Design and Engineering Jessica Carr, Human Centered Design and Engineering, University of Washington Elena Agapie, Human Centered Design and Engineering Andrew Davidson, University of Washington

Andrew Davidson is a senior lecturer in human centered design and engineering at the University of Washington, specializing in physical computing and HCI. He directs the department's $\mathrm{K}-12$ outreach program, and is also a former high school computer science teacher.

\section{Dr. Jennifer A Turns, University of Washington}

Jennifer Turns is a Professor in the Department of Human Centered Design \& Engineering at the University of Washington. She is interested in all aspects of engineering education, including how to support engineering students in reflecting on experience, how to help engineering educators make effective teaching decisions, and the application of ideas from complexity science to the challenges of engineering education. 


\title{
Coordinated Outreach: A Model of STEAM Outreach Efforts
}

\begin{abstract}
Dedicated, ongoing, and coordinated outreach efforts are critical to increasing the participation of underrepresented students in STEAM fields. Researchers have called attention to the collaborations between K-12 and higher education sectors that seek to promote college access, particularly among underrepresented students [1]. In our research, we collected reflective accounts from seven graduate outreach coordinators in an engineering department at a public university involved in STEAM outreach to pre-college students. Understanding how people are approaching the expansion of their STEAM outreach can be valuable to those interested in supporting STEAM outreach efforts in their own contexts.
\end{abstract}

We set out to reflectively trace the history of efforts led by graduate outreach coordinators, the current questions outreach coordinators are facing, and aspects of hidden internal knowledge that exists among our collective outreach efforts. For this investigation, we ask:

What do key considerations, tensions, and opportunities from graduate outreach coordinators suggest about the infrastructure and growth of our K-12 STEAM outreach efforts?

To answer this question, we drew on a multiple perspectives methodology [2] in which we collected reflections from the graduate outreach coordinators, who led key efforts in the outreach program (e.g., those who designed the initial activities, scaled the outreach efforts to different states, first launched classroom workshops, and/or established library partnerships). Each participant created a reflective account of their experiences. Core to our research is the thematic analysis of the first-hand accounts of the graduate outreach coordinators' experiences [3] in scaling outreach efforts through partnerships to make diverse perspectives visible.

In our discussion section of this work we propose a model of our K-12 STEAM outreach efforts that helps us think about the ways in which each graduate coordinator influences the outreach program while maintaining a core vision and commitment. The implications of this work can support engineering educators involved in pre-college STEAM outreach efforts to consider how design at the infrastructure level can support and attract under-represented students.

\section{Introduction}

University and department context

The Human Centered Design and Engineering department partners with regional K-12 schools in activities designed to engage pre-college students and their teachers in the field of humancentered design. The outreach activities include conducting human centered design (HCD) workshops in K-12 classrooms [4]. Prior research has described how the program has been 
perceived positively by K-12 students and their teachers [5]. K-12 students enjoy the workshops, not only for the hands-on design activity, but also because they are able to have natural interactions with college students.

The "charrettes," a fast-paced design activity, are used as a way to introduce students to the human centered design process. In the "HCD Charrette," students are given a particular design space to explore (such as user interfaces for a website, mobile app, or a physical device). In a very short period of time, working in small groups, they brainstorm user needs, develop scenarios, and create prototypes for a mobile application. To date, these workshops have been run with K-12 students across Washington state. The workshops are facilitated by undergraduate students under the leadership of a graduate coordinator and the supervision of Professor Davidson (co-author).

For the past six years, this program has been run quarterly as a part of a seminar in the department. Undergraduate students enrolled in the seminar help create the materials to present in the HCD workshops and then facilitate these workshops in K-12 classrooms. However, the positive impact of the outreach program has not only been realized by these undergraduate students delivering the workshops in the community. Professor Davidson in the department has been a consistent champion and leader of this STEAM outreach program for the last six years. Professor Davidson developed the outreach activities and has been core in developing the goals and values of this outreach program.

The graduate coordinators are Ph.D. or Master's students who, every year or quarter, join Professor Davidson to be active leaders in the outreach efforts. The graduate coordinators lead a group of undergraduate students in delivering the charrettes during each quarterly seminar. These graduate coordinators also model the creation and delivery of workshops through which outreach is enacted and maintain the program through each quarter of the seminar. Graduate coordinators support the outreach seminars for periods extending from one to four academic quarters. These graduate coordinators of the outreach program help design the workshop activities, establish partnerships with schools and institutions where outreach is conducted, guide undergraduate students to become facilitators, and help expand the program to new institutions and through new types of workshops. Transitions between the different graduate coordinators has required passing along complex information. As such, the need to accurately record our historical processes over the course of our outreach program.

\section{Outreach efforts overview}

Our K-12 outreach program has had a broad impact across the Puget Sound region. Young people from under-represented communities might not see themselves as college bound or know the pathways for pursuing STEAM fields. We see this as part of a pipeline problem and believe outreach should occur as early as elementary school to disrupt negative perceptions that these 
young students might have of their potential for higher education. Our K-12 outreach program has allowed us to engage with young people in under-represented communities as early as possible. Secondly, we have realized that human centered design as a college major is not well known among typical pre-college students. If students do not discover the department until well into their college careers, this does not allow them to have an opportunity to start thinking about career options in this field early enough so they can take courses and set their sights on it.

Having hands-on, interactive STEAM workshops in this field has brought awareness of design engineering and human centered technologies. We offer an introduction of human centered design at a more formative age. Most importantly, from a service-learning perspective in engineering, outreach can be beneficial for undergraduate facilitators, students who lead the workshop in the community, since their reflection on the outreach experience can benefit their own learning. Facilitating these workshops allows for intimate connections and conversations with the community and empowers facilitators to become change makers and leaders.

Outreach efforts genesis

Here, Professor Davidson reflects on the genesis of the STEAM outreach program.

This K-12 outreach program emerged directly from my experiences as a high school teacher before joining the university. In that role, I saw many examples of ineffective college outreach efforts directed at high school students. Talking to-or worse, atteenagers is not a good strategy for engaging them and influencing their ideas and behaviors.

The most effective outreach activities were hands-on and participatory, where the students could experience something about a discipline and imagine themselves in that role in the future. It opened their eyes to new possibilities. Inviting college students into my high school classroom to conduct these activities was far and away the most effective method of outreach I saw in the high school.

When I joined the university as a faculty member in human centered design and engineering, I started taking small groups of undergraduate students out to classrooms to lead workshops with $K-12$ students. (I was certainly not the first college professor to engage in outreach, but our small department had not done this kind of organized activity before.) At first, I went back to schools and classrooms where I had contacts and a network. These were typically upper middle class schools where many students were already college bound.

As the program grew, we branched out to middle and elementary schools and landed in some communities with much larger contingents of under-represented students and lower 
socio-economic status. I quickly saw that, for those K-12 students, the value of our workshops went beyond introducing them to STEAM fields. Their engagement with college students may have caused them to see themselves as potential college students, where before they might not have had that self-perception.

From that point on, we shifted our focus to actively trying to concentrate our outreach efforts in those communities and for those young students. A short summary of our outreach efforts may be found in [4].The research reported in this paper is part of our efforts to quantify the value of this work and to understand how we might scale this project up to have a greater impact than it has so far.

\section{Research efforts overview}

The intent of this research project was to document the stories of outreach graduate coordinators over the past six years. We hypothesized that by capturing the stories of the graduate coordinators we might be able to paint a linear picture of the outreach efforts of the program over time. Yet, after hearing stories and experiences from each graduate coordinator through their reflective accounts, we learned that the narrative of the process did not indicate a direct path or clear linear process.

Thus, in capturing reflective stories from each coordinator, we developed and thus, propose a model that describes how each graduate coordinator maintains the STEAM outreach program goals, while contributing their own personal interests and values to develop and grow the program. Our findings have implications for how we understand our organization at an infrastructure level and how graduate coordinators play a role in its growth. Findings from this work surface areas for growth and development of future K-12 outreach programs. Our contributions of this work are scoped at an infrastructural level through the lens of the graduate coordinators. Future work can explore training of the undergraduate facilitators and graduate coordinators and the impact of our outreach efforts for K-12 education. Engineering education community members who are interested in developing and sustaining robust outreach programs in their own contexts might find our proposed model helpful for inspiration.

\section{Related Work}

Outreach efforts in the context of universities

To increase the percentage of students from under-represented backgrounds in STEAM, many universities engage in K-12 outreach efforts [6]. Within the engineering education community, ASEE President Jakubowski called attention to the need for K-12 education outreach efforts and the organization's role in improving research on these efforts [7]. A study in 2011 highlights the recent increase in faculty members' willingness to participate in these outreach efforts [8]. Other research efforts focus on understanding the student experience of these outreach efforts and the 
potential for increasing access and opportunities to different communities [9]. Another branch of research within engineering education outreach efforts focuses on the development of tools to help guide the formative assessment of STEAM outreach programs [10]. Yet, from our review of existing literature in engineering education, research on outreach efforts tends to focus on STEAM curriculum assessment and impact for students engaged in the outreach efforts, and few explore the experiences of graduate coordinators guiding these outreach efforts within university contexts [11].

\section{Understanding impact of outreach efforts}

Engineering outreach efforts can take a variety of forms, with different kinds of curriculum developed and delivered through programs like service-learning [6]. As institutions of higher education develop partnerships with different community agencies, scholars have sought to understand the impact of these partnerships [12]. In our work, from a review of the engineering education literature, we often found research that explores the impacts of outreach efforts is often closely connected to research on service-learning. Service-learning as defined by Jacoby [13] is "a form of experiential education in which students engage in activities that address human and community needs together with structured opportunities intentionally designed to promote student learning and development." Furthermore, partnerships with K-12 schools are one of the more common types of service-learning programs in engineering [14]. We see similarities and differences between our HCD charrette outreach efforts and service-learning in engineering education. For example, our outreach efforts center design and include meeting societal needs as a mission of the profession [15]. Yet, traditionally service-learning in engineering education connects what students learn in a particular classroom to carry out projects in communities, while our efforts are on-ongoing beyond a single course or classroom. In reviewing existing research on the impact of outreach efforts, we often found literature focused more in the impact of service-learning efforts at large. We note that not all engineering outreach efforts can be considered service-learning efforts.

Anecdotal evidence suggests that outreach is impactful and there is value for both those who develop the materials (undergraduates and graduate students) and those who receive it (K-12 learners). However, it has been a challenge for researchers to find ways to conceptualize servicelearning and find it's measurable outcomes [12], [16]. Part of this challenge is that servicelearning and outreach is spread across many organizational components (e.g., students, the department, communities and professors) [12]. Furthermore, it can be difficult to understand the underlying intent or goals of a service-learning effort [17]. Scholars are still exploring how to understand the different aspects of what service-learning is and how these aspects are related to each organizational component and to the positive outcomes of engineering education [18]. Driscoll and colleagues offer a comprehensive case study model of their work at Portland State University to outline mechanisms which support measuring impact of service-learning efforts [12]. In their work, researchers developed variables in a participatory fashion with their different 
constituents (students, faculty, community, and institution) to understand what their impact looked like [12]. Building on this body of literature which explores the process of measuring impact at the service-learning level, the goal of this paper is to begin to understand the organizational infrastructure of our K-12 STEAM outreach efforts by documenting stories from the graduate coordinators of a K-12 outreach program. The findings from this work help build a taxonomy of the program for potential future research which explores its impact on multiple constituencies (undergraduate students, graduate students, faculty, community, institution).

\section{Methods}

Approach

To answer our research question and gather insights from past graduate coordinators of the outreach efforts, we sent out a recruitment email to all of the past graduate student coordinators. The email described the project as an effort to capture their experiences with the charrettes, facilitated through a reflection activity. Through a scaffolded reflection activity, we invited them to think about their efforts leading the charrettes. We provided them with prompts to help them remember, name, and unpack their experience: When did you lead the charrettes? Where did you lead the charrettes? What lessons did you take away? What surprises did you experience? How did leading the charrettes impact you? After considering these questions, graduate outreach coordinators documented their thoughts to a collective online notebook. Along with their written notes, we also asked them to submit an image of their choosing that helped capture their ideas from the reflection activity. For graduate coordinators who were unable to contribute to the online notebook, we asked them the same set of questions during a semi-structured interview.

\section{Participants}

After three email requests, seven out of eight graduate coordinators responded to our request for generating a reflective account of their experience or being interviewed following the online prompts. All names used in the paper are pseudonyms. Verbal and/or written consent was obtained from each participant to use their accounts as analysis for this work. This human subjects research was also considered exempt by our university institutional review board.

\section{Data analysis}

Inspired by a multiple perspectives methodology [2], we collected reflective accounts from seven graduate coordinators. To analyze the data, two researchers used open coding with constant comparative analysis [19]. These two coders were among the seven graduate coordinators that chose to participate in the reflection exercise. Following open coding, we used axial coding to make connections between graduate coordinators' reflective accounts, existing literature on outreach efforts in engineering education research, and our own experiences participating as graduate coordinators in the outreach program. We identified key findings from our research investigation and summarized four compelling stories from the experiences of the graduate 
coordinators. These stories bring to light important considerations, tensions, and opportunities in our coordinated outreach efforts over time. We engaged in peer scrutiny of our findings with each graduate coordinator to ensure trustworthiness in our work [20]. We then propose a model of STEAM service-learning efforts synthesized from these findings.

\section{Part I. Findings from reflective accounts}

\section{Conceptualizing leadership}

Consideration. Graduate outreach coordinators held different definitions of their responsibilities as an outreach leader. Some viewed the role as strategic and established foundational pieces of the program or ways they could extend and grow the program during their leadership tenure. On the other end of the spectrum, some graduate coordinators were more executional in their approach and focused on the work they would do with undergraduate students and community partners during the shorter cycle of an academic quarter. Other graduate coordinators held views that mixed elements from each of these approaches.

Tension. When the graduate outreach coordinator's focus was more strategic, they were attentive to the long-term growth and administration of the program. Examples of activities that contributed to the growth include initiating contact with new community partners, creating databases to document the who/what/where/when of past workshops, and extending materials to aid in teaching different layers of the charrette (e.g., teaching other graduate coordinators how to lead undergraduates to teach K-12 students). Yet, when the focus was more executional, graduate outreach coordinators repurposed materials to fit their quarterly needs, often piloting new ideas and incorporating their personal passions (e.g., teaching experience, mentoring, supporting public schools and libraries, research opportunities). Without a strict definition of what the graduate outreach coordinator was supposed to do, the program functioned and grew organically, in productive but unstructured or unsystematic ways.

Opportunity. Supporting a flexible definition of how graduate coordinators scope and execute on their responsibilities, the program has managed to create more ways to participate, allowing graduate coordinators to customize the level of leadership that worked for them. This flexible model is structured to enable inclusivity and diversity in leadership roles. Working at the rapid pace of the academic calendar has also highlighted the need to purposefully attend to the administrative maintenance of the growing program, and to carve out time to do the work of strategic curation and long-term planning.

Reflection. Discovering that our graduate outreach coordinators are all doing the work differently has offered us a new insight into the program and the ways in which it aligns with the core value of inclusivity in the program. We also wonder if this leadership model is also a result of the program's consistent leadership from Professor Davidson. Each quarter he asks graduate 
coordinators "What do you want to get out of this experience?" He then works to support and encourage that in a hands-off manner. The invitation to lead makes us reflect that this flexible leadership model may actually be "by design."

Transitioning from graduate coordinator to graduate coordinator

Consideration. The student body population in a university setting shifts at the start of every academic year, with a new cohort of students joining the culture and a graduating cohort leaving their legacy behind. In the case of our outreach efforts, leadership positions are held by current graduate students in our department and turnover can occur every quarter. We considered how outreach materials (the design challenge, charrette materials, seminar organization, and seminar lecture slides) are passed down during this turnover period.

Tension. We learned that for most of our graduate outreach coordinators, the beginning of the quarter was a challenging time of transition with respect to the shared materials they received from the previous graduate coordinators. As graduate coordinators tried to attend to and highlight their own values in their efforts, they also attempted to remain consistent with the overarching goal of the program and build on prior graduate coordinators' efforts. This proved challenging when taking existing materials like seminar lecture slides and deciding whether to modify many aspects of the materials or start new ones. Another thing we have noticed is that using an internal spreadsheet to document information about all of the workshops in each quarter has been a challenge for every graduate coordinator. This transition can become messy as graduate coordinators decide how to blend their own values with those of prior graduate coordinators and the overall goals of the program.

Opportunity. This realization has led us to ask how we might design a tool that supports the collection and analysis of impact over the course of rapid and frequent transitions between graduate coordinators. We believe this transition period offers new learning and professional development opportunities for each graduate coordinator to understand the central value and mission of the program. Each transition period allows graduate coordinators to study what was passed down and use what is valuable, while adding their personal touch for the kinds of educational engagements they want to highlight during their tenure.

Reflection. Elizabeth gave all of her materials to Tania. Elizabeth had every week planned out and prepared lecture slides that could be modified for the next year. But the transfer of materials was not seamless because Tania decided to take a different approach than Elizabeth with respect to the kinds of schools, they visited during the outreach efforts. In trying to adapt Elizabeth's materials, Tania realized that she did not need slides for every week, given her approach to leading the seminar in a more activity-based setting. Tania reflected that although valuable as a starting point, the materials were not as easy to adapt to the specific school context and different timeline. For the first couple of weeks, Tania did use the lecture slides to start off, but as the 
weeks went on, based on the engagement with schools and teachers, she generated her own materials that were later passed on to Angie. Tania reflected that she did see the value in passing on materials because she might have been overwhelmed if she had not been given anything when she first started, but with the caveat to future graduate coordinators that they should feel empowered to adapt the materials according to their own goals within the program. Here, we emphasize that different priorities and goals does not mean some graduate coordinators were disinterested in the program. Rather, all graduate coordinators shared this latitude in the focus and priorities as a positive aspect of our outreach efforts.

Communication between graduate coordinators and community members Consideration. Professor Davidson strives to give agency to each graduate coordinator by allowing them to structure and lead the seminar, to have a say in choosing the seminar students who will visit the schools during the quarter, and by inviting graduate coordinators to bring different learning contexts to the program. This freedom to create new partnerships with a commitment to cultivating existing relationships leads to another consideration for communicating with community partners during turnover periods. As the outreach program continues to expand to new locations and strengthen existing partnerships, there is a question of communication channels and points of contact.

Tension. We noticed a tension between community members when they were confused about their point of contact in the program. Some of this confusion resulted from Professor Davidson re-directing communications from a teacher to a new graduate coordinator. Other times graduate coordinators wondered if they could establish new partnerships or if they should go to similar locations as the previous year. Expanding to new locations introduces new challenges of communication and consideration of variables that can make following existing protocol and processes seem like an easier path for graduate coordinators to take.

Opportunity. We believe there is opportunity for each graduate coordinator to leverage existing connections with community members, but also to feel empowered to build new relationships with different communities of interest and connect them to the larger program infrastructure. With approaches to establishing new community partnerships, there needs to be support from Professor Davidson, willingness from the undergraduate students, and willingness to take risks by the graduate coordinators (e.g., risk of reaching out to community members and not getting responses).

Reflection. Over the course of an academic year, Tania, Justine, and Angie noticed there was a lack of growth over time and felt the outreach program was doing things without necessarily expanding. Justine and Tania reflected on the ease that comes from falling into the established norms versus the additional work that needs to be done when starting new partnerships. For example, when Tania decided to go into the community college setting, she had a conversation 
with Professor Davidson about whether this context fell within the established goals of the outreach program. At first glance, community college students appear to be outside of the K-12 realm. After going through with the new partnership, Tania realized there were actually a lot of

Running Start students in community college courses-students who had high school standing but were taking college courses. Challenging assumptions about the contexts for the outreach program, this was an opportunity to reach a different population of students that we had not worked with before. Yet from the graduate coordinator reflections, we learned that in addition to the value of establishing completely new partnerships, there is a lot of thought and intentionality that needs to go into redesigning the curriculum to adapt to new classroom dynamics we might not yet have experienced. Our materials for the outreach efforts have primarily been designed for middle schools. In Tania's reflection she noted the requirement to develop a curriculum that honored the adult perspectives of the community college students while still maintaining the spirit of a charrette.

Impact beyond anecdotal evidence

Consideration. Through word of mouth, connections, and increasing numbers of people participating in the outreach program, we continue to grow substantially. We are at a point where we are asking "What is our impact? How do we see, how do we communicate, and how do we share our impact?" Taking this consideration into account and coupling it with the value of reflecting on our history as we move forward, we set out to listen to the reflective accounts of past graduate coordinators. After six years, we have a collective desire to grow beyond what we have already accomplished and established. We want to be innovative in our approach, our partnerships, and our leadership as we grow.

Opportunity. This project was an opportunity to document and preserve the stories and reflections of the graduate coordinators engaged in our outreach efforts. We see value in stepping back before moving forward in our efforts. Learning from graduate coordinators who came four or five years before us can provide an opportunity to trace the history of our efforts. We believe we can be creative and responsive to our needs, and to measure impact beyond numbers.

Tension. But in this endeavor, we did not end up mapping out the history of outreach graduate coordinators. In fact, after reading each graduate coordinator's reflections we learned that each of us had a journey that was influenced and informed by prior graduate coordinators, but was unique to our passions, interests, and commitments. There is no definitive beginning, middle and end to the history of the outreach program. We see an opportunity to be creative in how we measure impact beyond numbers, while continuing to grow and keep a central focus on the people leading our efforts. 
The lack of knowledge and documentation around the scope of our impact over the past six years has led us to a commitment of powerful and collective efforts toward future research about and development of the program.

Reflection. Given this heightened awareness and attention to considering our history as we reflect on where we are today as an outreach program and envision where we might go next, we have embarked on a new journey to explore alternative ways to measure our impact. One approach is through the collective writing of this paper. In other efforts we will try to connect with past graduate coordinators through a new mixed-methods study. Over the past six years, we have accomplished much, but now we're carving out space and time to really reflect and consider our actions, decisions, and our impact. In what follows, we propose a model for understanding the key takeaways from our findings.

\section{Part II. A model of STEAM outreach efforts}

The key aspects of our graduate coordinators' reflective accounts (concepts of leadership, transitions between graduate coordinators, communications with community members, understanding impact) have shown us that there is a unique infrastructure and developmental model at play in these K-12 outreach efforts. For example, as graduate outreach coordinators establish new partnerships with community members, they might consider their current role while also taking into account future communication, training, and how the activity will be shared with a new graduate coordinator.

We interpret our growth represented not by a linear progression of time, but rather growth as expanding. Each quarter, individuals and groups of undergraduate students, graduate coordinators, community partners, and professors add their own unique perspectives and priorities. From a reflexive perspective, as we reviewed our findings, we came to the conclusion that we could not fit the story of the graduate coordinators into a linear timeline. In making sense of the implications from our findings, we noticed the narrative of outreach efforts involves more than just the graduate coordinators. The collective insights from this research led us to propose a model of STEAM outreach expansion efforts, demonstrated in Figure 1 below. We do not propose that this model of STEAM outreach expansion efforts is generalizable. Rather, we ensure credibility of our qualitative inquiry [21], by demonstrating a true picture of the phenomenon under scrutiny with the presentation of thick description in our findings and model. 


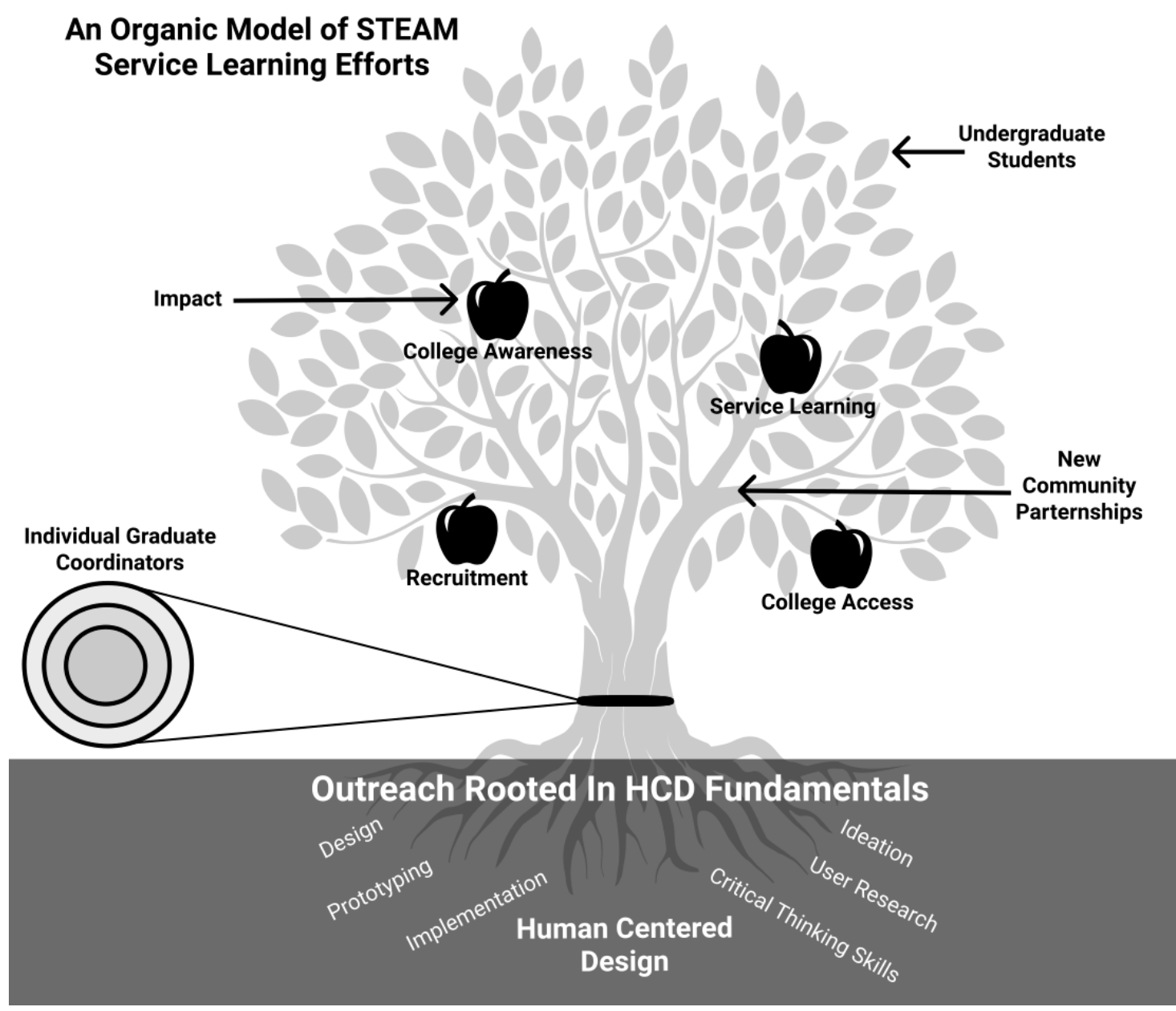

Fig 1. A model of STEAM outreach expansion efforts

We represent the development of the outreach program as organic, where change comes gradually as we gain new partnerships and develop new activities, similar to a growing tree. In design, metaphors help us make sense of complex issues and start conversations with important people. This tree model demonstrates the cyclic process of human centered design outreach. Beginning with the roots of the tree, we ground ourselves in the principles of human centered design. We teach K-12 students these key fundamentals through our workshops, and also embrace them to maintain our outreach organizational structure. Through ideation, iteration, and prototyping, we curate new workshops to help best fit the needs of our community partners.

From these roots, we develop values and principles that began with the ideas developed at the outset of the outreach program by Professor Davidson. In this tree model, Professor Davidson is the foundation or trunk of the outreach program.

As the tree continues to grow, its rings represent each quarter of our outreach efforts. These efforts are connected to each other, but the connecting fiber of the rings is not always transparent 
or evident. Each ring of the tree holds its own history. Each quarter there is a transfer of values, priorities, and materials, much may be lost in the transition. However, this loss leads to new values and priorities being developed by each new graduate coordinator. Each person that shared their reflective accounts brought their own personal interests and values to bear on the program. This helps create a unique flavor for each quarter.

Each quarter, the graduate coordinator and undergraduate students work together to reach out to existing partners and contact new ones. The development of the tree leads to the growth of new branches. Each quarter new experiments help build new partnerships or create branches of our outreach program. For example, during Summer 2018, Justine wanted to find a way to reach out to communities beyond classrooms. That quarter Justine reached out to libraries. Our partnership with Seattle libraries is now a growing branch of our outreach program.

The unique flavor of each quarter allows for workshop materials to evolve based on the values of the graduate coordinators, but they also retain the original framework of the workshops created by Professor Davidson who initially developed them. The outreach program is well supported by the academic department and the founding professor provides continuity as the program grows. This can be seen as the nourishing soil in our model.

Each new quarter of the program takes on a distinct character, much as the flavor of apples on the tree varies in each year's harvest. This flavor is influenced by a new group of undergraduate students each quarter, who bring new social dynamics to the research group. Each new student who participates in the research group can be seen as a leaf of the tree. Eventually, students leave the program and become part of the community at large. Similarly, leaves will eventually fall off and become part of the soil.

The outreach program has had an impact on the broader community from its start, including both K-12 and undergraduate students. Metaphorically and through our model we represent that the tree has produced fruit. The outreach program was developed to help recruit students into the field of human centered design, to highlight college awareness and access, and to give undergraduate students the opportunity to participate in service-learning activities.

\section{Discussion}

From our research with the graduate outreach coordinators and developing our model of STEAM outreach expansion efforts, we highlight three main takeaways.

First, our outreach efforts have allowed each graduate coordinator to bring their own flavor and interests to the program, while remaining true to the guiding values established in the program. Every quarter, while there are differences in the graduate coordinators and undergraduate students, they all work on the shared goal of K-12 outreach. For example, Professor Davidson 
emphasizes the program's commitment to helping students who might benefit most from our efforts, given our mandate as a public state university. Our guiding force is to help students in the entire state access college, and to promote and educate them about our department. Our department commitments are centered on people, design, iteration, innovation, and collaboration. These commitments infuse every quarter of the program. With each new quarter, we expand our goals and efforts.

Secondly, in attempting to trace a history of the program, we learned that every quarter had a different story. Some graduate coordinators spent more time developing promotional material, others experimented with new partnerships. However, each transition coupled with the consistent leadership of the professor meant that there still exist common values that help maintain consistency across the program quarters.

Lastly, the workshop materials and the transitions between graduate coordinators help keep the overall program sense, even as graduate coordinators take on additional responsibilities. They manage coordination with schools, lead the undergraduate students to different areas, and train them. While this creates responsibilities for them, this contributes to our innovation and adds a unique aspect to our outreach organization. As an outreach program, we embrace growth and change, and are constantly evolving.

\section{Conclusion}

From close engagements with reflective accounts of seven graduate coordinators in these outreach efforts and in attempting to trace our history, we learned that our organization does not have one clear linear timeline. Rather we have focused our efforts as a collective group working on shared values to understand the shared space of outreach, service-learning opportunities, and community engagement. We propose a model of STEAM outreach efforts that traces the cyclic and collaborative nature of our organizational infrastructure as leaders of these efforts. We invite future discussion on our model by other outreach coordinators to support the growth and expansion of their K-12 STEAM outreach efforts.

\section{Acknowledgments}

We thank all the graduate coordinators for sharing their experiences with us and their valuable contributions to the growth of the program. We thank all who have contributed to HCDE's outreach efforts over the years. Furthermore, we greatly appreciate the insights and efforts of the students of the 2020 Outreach Impact Directed Research Group: Aiza Ali, Sara Gustafson, Kenny Le, Valerie Remaker, Pukhraj Sidhu, Sarah Tam, Cindy Zhao. 


\section{References}

[1] A.-M. Núñez and M. Oliva, "Organizational collaboration to promote college access: A P20 framework," Journal of Hispanic Higher Education, vol. 8, no. 4, pp. 322-339, 2009.

[2] R. Adams et al., "Multiple perspectives on engaging future engineers," Journal of Engineering Education, vol. 100, no. 1, pp. 48-88, 2011.

[3] J. A. Turns et al., "Reflecting on reflection: How educators experience the opportunity to talk about supporting student reflection," presented at the 2016 American Society for Engineering Education annual conference and exposition, 2015.

[4] E. Agapie and A. Davidson, "Human-centered design charrettes for K-12 outreach," interactions, vol. 25, no. 6, pp. 74-77, 2018.

[5] E. Rose, A. Davidson, E. Agapie, and K. Sobel, "Designing our future students: Introducing User Experience to teens through a UCD charette," in Proceedings of the 34th ACM International Conference on the Design of Communication, 2016, pp. 1-6.

[6] A. T. Jeffers, A. G. Safferman, and S. I. Safferman, "Understanding K-12 engineering outreach programs," Journal of professional issues in engineering education and practice, vol. 130, no. 2, pp. 95-108, 2004.

[7] G. S. Jakubowski, "Is there a role for ASEE in K-12 education?," ASEE Prism, vol. 11, no. 5, p. 41, 2002.

[8] B. Moskal and C. Skokan, "Supporting the k-12 classroom through university outreach.," Journal of Higher Education Outreach and Engagement, vol. 15, no. 1, pp. 53-75, 2011.

[9] J. C. Carroll et al., "Lessons Learned in K-12 Engineering Outreach and Their Impact on Program Planning (Evaluation)," presented at the 2017 ASEE Annual Conference \& Exposition, Jun. 2017, Accessed: Feb. 03, 2020. [Online]. Available: https://peer.asee.org/lessons-learned-in-k-12-engineering-outreach-and-their-impact-onprogram-planning-evaluation.

[10] E. N. Wiebe, M. Faber, J. Corn, T. L. Collins, A. Unfried, and L. Townsend, "A large-scale survey of K-12 students about STEM: Implications for engineering curriculum development and outreach efforts (research to practice)," in 2013 ASEE Annual Conference \& Exposition, 2013, pp. 23-59.

[11] E. Long, H. Goertz, S. C. TerMaath, and J. G. Coder, "Experiential Learning for Engineering Students through Educational Outreach and Leadership," in AIAA Scitech 2020 Forum, 0 vols., American Institute of Aeronautics and Astronautics, 2020.

[12] A. Driscoll, B. Holland, S. Gelmon, and S. Kerrigan, "An assessment model for servicelearning: Comprehensive case studies of impact on faculty, students, community, and institution," Michigan journal of community service learning, vol. 3, no. 1, pp. 66-71, 1996.

[13] B. Jacoby, Service-Learning in Higher Education: Concepts and Practices. The JosseyBass Higher and Adult Education Series. ERIC, 1996.

[14] M. S. Pritchard and E. Tsang, "Service learning: A positive approach to teaching engineering ethics and social impact of technology," age, vol. 5, p. 2, 2000.

[15] E. Tsang, C. D. Martin, and R. Decker, "Service Learning as a Strategy for Engineering Education for the 21 st Century," in 1997 Annual Conference, 1997, pp. 2-355.

[16] L. J. Bottomley and E. A. Parry, "Assessment of an engineering outreach program: Hands on engineering," Proc. American Society for Engineering Education, ASEE 2002, 2002. 
[17] D. E. Giles Jr and J. Eyler, "The impact of a college community service laboratory on students' personal, social, and cognitive outcomes," Journal of adolescence, vol. 17, no. 4, pp. 327-339, 1994.

[18] A. R. Bielefeldt and N. Canney, "Impacts of service-learning on the professional social responsibility attitudes of engineering students," International Journal for Service Learning in Engineering, Humanitarian Engineering and Social Entrepreneurship, vol. 9, no. 2, pp. 47-63, 2014.

[19] S. B. Merriam and E. J. Tisdell, Qualitative research: A guide to design and implementation. John Wiley \& Sons, 2015.

[20] J. Walther, N. W. Sochacka, and N. N. Kellam, "Quality in Interpretive Engineering Education Research: Reflections on an Example Study: Quality in Interpretive Engineering Education Research," Journal of Engineering Education, vol. 102, no. 4, pp. 626-659, Oct. 2013, doi: 10.1002/jee.20029.

[21] A. K. Shenton, "Strategies for ensuring trustworthiness in qualitative research projects," Education for Information, vol. 22, no. 2, pp. 63-75, Jul. 2004, doi: 10.3233/EFI-200422201. 